\title{
Cross-linguistic transfer in bilinguals reading in two alphabetic orthographies: The grain size accommodation hypothesis
}

\author{
Marie Lallier $^{1}$ • Manuel Carreiras ${ }^{1,2,3}$
}

Published online: 12 April 2017

(C) Psychonomic Society, Inc. 2017

\begin{abstract}
Reading acquisition is one of the most complex and demanding learning processes faced by children in their first years of schooling. If reading acquisition is challenging in one language, how is it when reading is acquired simultaneously in two languages? What is the impact of bilingualism on the development of literacy? We review behavioral and neuroimaging evidence from alphabetic writing systems suggesting that early bilingualism modulates reading development. Particularly, we show that cross-linguistic variations and cross-linguistic transfer affect bilingual reading strategies as well as their cognitive underpinnings. We stress the fact that the impact of bilingualism on literacy acquisition depends on the specific combination of languages learned and does not manifest itself similarly across bilingual populations. We argue that these differences can be explained by variations due to orthographic depth in the grain sizes used to perform reading and reading-related tasks. Overall, we propose novel hypotheses to shed light on the behavioral and neural variability observed in reading skills among bilinguals.
\end{abstract}

Keywords Bilingualism - Reading development · Orthographic depth · Grain size

Marie Lallier

m.lallier@bcbl.eu

1 Basque Center on Cognition Brain and Language (BCBL), Paseo Mikeletegi, 69, 2, 20009 Donostia, San Sebastián, Spain

2 Departamento Lengua Vasca y Comunicación. UPV/EHU, Bilbao, Spain

3 Basque Foundation for Science (Ikerbasque), Bilbao, Spain
Reading acquisition involves the recruitment and coordination of multiple cognitive and neural resources to build up fluent letter-to-sound mappings. However, the development of these complex mechanisms is not equal across languages. In alphabetic orthographies, the degree of difficulty affecting reading acquisition is modulated by factors linked to the complexity of letter-sound associations and to the size of the grain used in reading and reading related tasks. Although research has endeavored to improve our knowledge of reading acquisition across languages in monolingual settings, the number of behavioral (and neuroimaging) studies that look at reading development in bilinguals is rather scarce, making this population a clear outlier in this field of research. However, the rapid increase in the number of children acquiring reading in two languages simultaneously begs for more research on this question. The main goal of this article is to complement classic monolingual-centered research and take a step forward in proposing a novel framework on reading acquisition in bilinguals that will help to address unresolved questions on this topic: Namely, does bilingualism affect reading acquisition? And, if so, how does this influence manifest itself?

In that aim, first, we present work that highlights the cognitive and neural bases of reading skills and reading subskills (auditory phonology and visual attention) in the context of monolingual and bilingual reading acquisition in alphabetic orthographies. Second, we review behavioral and neuroimaging evidence in monolinguals and bilinguals showing how orthographic-specific modulations shape the use of reading strategies and the size of the grain used in reading and reading-related tasks. Third, we propose the grain size accommodation hypothesis, which should contribute to predicting the manifestations of cross-linguistic transfer in the development of reading in early bilinguals. 


\section{Neural and cognitive networks of reading skills and subskills}

\section{Reading skills}

In all alphabetic writing systems, the reading procedure (or strategy) referred to as "phonological decoding" whereby children decipher the phonology of unfamiliar orthographic strings provides the bases for reading acquisition. Solid phonological decoding skills will foster, through a self-teaching mechanism, the development of an orthographic lexicon to enable fast and fluent reading (Share, 1999, 2004; Ziegler, Perry, \& Zorzi, 2013). Consequently, efficient orthographic and phonological cognitive processes are necessary to crack the orthographic code and learn to read fluently. Two orthographic routes may be used to access phonological representations. On the one hand, fine grain orthographic coding of graphemes and their respective order in a word is responsible for retrieving phonemes and accessing whole-word phonology. On the other hand, coarse grain orthographic computations will process the necessary information to guess the orthographic and phonological identity of a word as a whole (Grainger \& Ziegler, 2011).

Therefore, the brain signature of learning to read should illustrate how beginner readers progressively tune the neural populations in charge of the mapping between orthography and phonology - that is, between graphemes and phonemes, in the case of alphabetic languages. In fact, good functional and structural connections between brain areas subtending grapheme-to-phoneme mapping is essential to develop reading in alphabetic languages (Thiebaut de Schotten, Cohen, Amemiya, Braga, \& Dehaene, 2014).

As a consequence of active use and exposure to graphemeto-phoneme mappings, activity around a small area located in the left ventral occipital-temporal (vOT) cortex (the so-called visual word form area, or VWFA; Cohen et al., 2002) has been shown to emerge (Brem et al., 2010). It has been proposed that the lateralization of this area to the left hemisphere reflects the influence of print phonology on the orthographic computations performed by neurons located in this visual region (e.g., Yoncheva, Zevin, Maurer, \& McCandliss, 2010). This is in line with the existence of a left-sided dorsal temporo-parietal network within the reading network, which includes the inferior parietal lobule and the posterior superior temporal region: The former would be specifically involved in attentional shifting linked to serial decoding mechanisms (Carreiras, Quiñones, Hernández-Cabrera, \& Duñabeitia, 2015; Richlan, 2014; Taylor, Rastle, \& Davis, 2013), whereas the latter may have a preferential role to play in grapheme-tophoneme mapping (van Atteveldt \& Ansari, 2014). As the amount of reading experience increases, the left vOT cortex takes control of the automatic retrieval of orthographic representations through parallel computations of the letters of orthographic inputs. Therefore, the left vOT cortex seems to be necessary for the development of the automatic recognition of lexical orthographic forms - that is, for the lexical reading procedure - in particular because it also connects with regions that perform lexico-semantic analysis (Yeatman, Rauschecker, \& Wandell, 2013), such as the left medial temporal lobe (Vigneau et al., 2006). Overall, the aforementioned reading network plays a central role in the acquisition of visual word identification (Carreiras, Armstrong, Perea, \& Frost, 2014; Jobard, Crivello, \& Tzourio-Mazoyer 2003; Sandak, Mencl, Frost, \& Pugh, 2004; Schlaggar \& McCandliss, 2007). Moreover, hypo-activation of parts of this network is the signature of reading disorders across languages (Richlan, 2014; Richlan, Kronbichler, \& Wimmer, 2009).

\section{Reading subskills: auditory phonology and visual attention span}

It is not clear whether the quality of neural activity and connectivity within this reading network is the proximal cause or a mere consequence of reading outcomes. In fact, it is important to note that the reading activity itself feeds from cognitive computations performed by several other brain areas that do not overlap with the neural circuitry described above. The cognitive skills (hereafter referred to as reading subskills) that arise from the activation of these areas represent the prerequisites of normal reading acquisition: they correspond to a pool of skills that are not directly engaging orthography-phonology mapping mechanisms and reading strategies per se, but without which the acquisition of such strategies would be delayed or impaired. A large amount of developmental research, including important work on developmental dyslexia, has highlighted several fundamental reading subskills that might independently contribute to reading acquisition, in line with a multifactorial approach to understand typical and atypical reading development (Bosse, Tainturier, \& Valdois, 2007; White et al., 2006; Wolf \& Bowers, 1999). Developmental dyslexia is diagnosed when an unexpected persistent low reading proficiency is achieved despite the absence of other factors that could explain the reading difficulties (i.e., sensory or psychiatric disorders, abnormal schooling, low IQ). Research trying to identify the proximal cause(s) of this reading disorder has shed light on the cognitive pre-requisites of reading acquisition. In light of such research, we will focus on two cognitive reading subskills, namely "auditory" phonology and visual attention.

Auditory phonology refers to processes that require the analysis of the sound structure of linguistic stimuli. These skills, acquired in infancy from the analysis of speech streams before any exposure to print takes place, are thought to contribute significantly to reading development and grapheme-tophoneme conversion in particular (Snowling, 2000, 2008). Therefore, an auditory phonological deficit would explain 
why dyslexic individuals fail to learn to read fluently (Ramus et al., 2003). So far, several phonological components have been identified and shown to contribute to reading development (i.e., phonological awareness, phonological short term memory, phonological access/fluency), although it is still a matter of debate whether they tap into independent constructs (Protopapas, 2014) or if they equally contribute to reading (Melby-Lervåg, Lyster, \& Hulme, 2012). Ramus and Szenkovits (2008) explored more deeply the nature of the phonological deficit and proposed that the access to phonological representations (and not the quality of these representations) is the core phonological problem in dyslexia (see also Ramus, 2014). A recent neuroimaging study supports this hypothesis. Boets et al. (2013) report that the left-sided brain network subtending phonological reading subskills - that is, the superior temporal gyrus and the inferior frontal gyrus - is less strongly connected in dyslexic than in skilled readers. Interestingly, these phonological regions are functionally and structurally linked to the reading networks (e.g., Cao, Bitan, \& Booth, 2008; Steinbrink et al., 2008; van der Mark et al., 2011; Vandermosten et al., 2012), which explains why their role in reading must be significant. Studies conducted across alphabetic languages report that these phonological abilities tend to have the strongest contribution to reading development at the first stages of reading acquisition, when most of the orthographic inputs are unfamiliar and need to be decoded phonologically (Bosse \& Valdois, 2009; Vaessen et al., 2010; Ziegler et al., 2010).

Unlike auditory phonology, the role of visual attention in reading has received less interest in developmental research and has been a subject of debate (Goswami, 2015; Skottun \& Skoyles, 2006). However, there is increasing evidence that visual attentional skills do contribute to literacy acquisition and that they may even play a causal role in reading outcomes (Franceschini et al., 2013; Onochie-Quintanilla, Defior, \& Simpson, 2017; Valdois et al., 2014). So far, research has highlighted two (possibly independent) main visual attentional components important for learning to read: covert spatial visual attentional shifting abilities and visual attention span skills (Lallier \& Valdois, 2012). First, covert spatial attentional shifting corresponds to spatial changes in the spotlight of attention occurring without eye movement. The idea is that visual attention is able to shift between different spatial locations within a string of letters while the eyes remain fixated. These covert visual attention skills would be mainly necessary for pseudoword reading and the use of phonological decoding strategies (Facoetti et al., 2006; Hari \& Renvall, 2001; Onochie-Quintanilla et al., 2017; Perry, Ziegler, \& Zorzi, 2010), since they would subtend the sequential orthographic parsing strategies that facilitate grapheme-to-phoneme conversions. In line with this idea, covert visual attentional shifting skills have been shown to correlate with auditory phonological abilities (Lallier, Donnadieu, Berger, \&
Valdois, 2010; Lallier \& Valdois, 2012). In relation to this, Richlan, Kronbichler, and Wimmer $(2009,2011)$ found a consistent atypical functioning of left dorsal inferior parietal sites in impaired readers (supramarginal gyrus in particular) that may be directly involved in sequential visual attention processes at play during phonological decoding (Richlan, 2014). This data is also in line with the classical involvement of the parietal junction in attentional shifting and orientation (Astafiev, Shulman, \& Corbetta, 2006; Corbetta \& Shulman, 2002; Mars et al., 2012). The second visual attention component, the visual attention span, contributes to reading independently from the aforementioned phonological skills (Bosse et al., 2007; Bosse \& Valdois, 2009) and the verbal nature of the stimuli to be processed (Lobier, Zoubrinetzky, \& Valdois, 2012). Visual attention span skills are defined as the number of visual elements that can be processed simultaneously in a multi-element array, and are classically measured with the global and partial report tasks (Bosse et al., 2007). In these tasks, an array of five visual elements is presented for no more than $200 \mathrm{~ms}$ (time for one fixation), and participants have to report either all the elements identified, with no order constraint (global report; see Fig. 1a), or a single cued element (partial report; see Fig. 1b).

These skills are thought to support the encoding of orthographic chunks as a whole in memory (Bosse, Chaves, Largy, \& Valdois, 2015). They would engage the simultaneous dimension of visual processing in contrast to the covert spatial visual attentional shifting skills presented above that would tap into sequential processing (Lallier et al., 2010; LassusSangosse, N'Guyen-Morel, \& Valdois, 2008). The superior parietal lobules have been shown to be recruited during tasks tapping visual attention span abilities, in line with the attentional interpretation of these skills (Peyrin, Démonet, N'Guyen-Morel, Le Bas, \& Valdois, 2011; Peyrin, Lallier, \& Valdois, 2008). Interestingly, the superior parietal lobule has not been directly ascribed to the reading network per se (unlike the inferior parietal lobule), but may instead be involved in the preorthographic processing of letter strings (Carreiras et al., 2014; Lobier, Peyrin, Le Bas, \& Valdois 2012; Reilhac, Peyrin, Démonet, \& Valdois, 2013). Accordingly, dyslexic adults and children with a visual attention span disorder exhibit a hypo-activation of the superior parietal lobule bilaterally, whereas the brain activity of dyslexic participants with a pure auditory phonological deficit exhibit a hypo-activation of the left inferior frontal gyrus (Peyrin et al., 2012). Its role would be potentially important when the letter strings are not presented in a familiar format and would therefore be in charge of the difficult analysis of multiple visual elements (Cohen, Dehaene, Vinckier, Jobert, \& Montavont, 2008) before their processing can be relayed by the left vOT cortex (see also Lobier et al., 2012, for a more detailed account of the role of the superior parietal lobules in reading and its connections with the left vOT area). In line with this idea, Yeatman et al. 


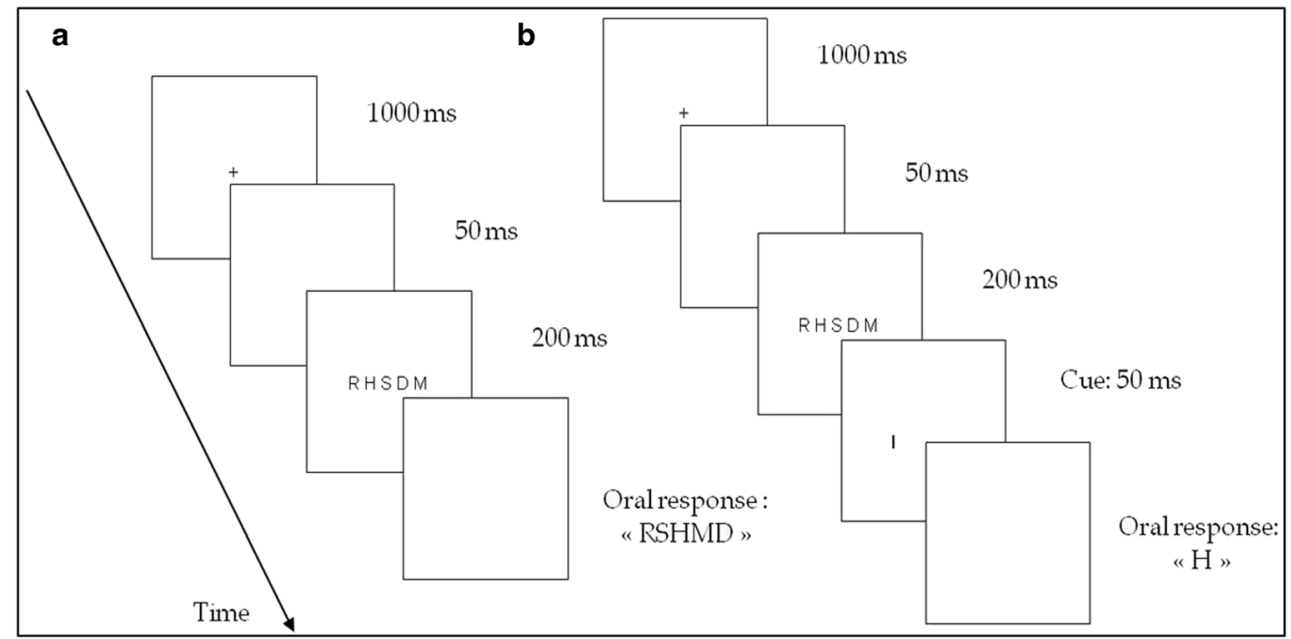

Fig. 1 Schematic illustration of the whole-report and partial-report tasks. a The whole-report task requires naming as many of the five consonants as possible, without order constraint. b The partial-report task requires a single cued letter to be named

(2014) reported the existence of a white matter tract that connects the vOT to the intra parietal sulcus.

Overall, research has shown that both auditory phonology and the visual attention span are cognitive reading subskills that contribute to typical and atypical reading development and whose brain underpinnings are connected to the areas of the classical reading network, although they do not generally overlap with it. ${ }^{1}$ Importantly, both a pure phonological deficit (i.e., without visual attention span impairment) and a pure visual attention span reduction (i.e., in the absence of any phonological deficit) are thought to potentially cause dyslexia (Valdois et al., 2003). However, the prevalence of either type of deficit may differ within a particular dyslexic population. For example, Saksida et al. (2016) showed that pure phonological deficits associated with dyslexia were actually much more frequent than pure visual attention span disorders in a French child population. However, Bosse et al. (2007) found relatively equal proportions of the two dyslexic types in French and British groups of children. Further studies will be needed, both within and across languages, to better characterize the scope of such a multifactorial hypothesis of dyslexia.

In the next section, we will describe cross-linguistic research in monolinguals and bilinguals. We will focus on the effects of orthographic depth (1) on reading strategies and (2) on reading subskills (specifically, on auditory phonology and visual attention span). The issue of cross-linguistic transfer based on orthographic-depth factors in bilinguals will be addressed subsequently.

\footnotetext{
${ }^{1}$ The left inferior frontal gyrus has been generally included in the reading network (e.g., Pugh et al., 2000), although its role in reading points toward access to auditory phonological representations, therefore also encompassing pure auditory phonological processing (Boets et al., 2013).
}

\section{Cross-linguistic differences in reading strategies: the role of orthographic depth and its consequences for processing grain size}

One of the most studied modulator of reading acquisition across languages is orthographic depth. Alphabetic writing systems differ on the complexity, consistency, and predictability with which the graphemes map into their corresponding phonemes (Schmalz, Marinus, Coltheart, \& Castles, 2015). In Spanish, a shallow orthography, these relations are (mostly) univocal: the letter "o" always converts to the sound /o/ and the phoneme /o/ is always written with the letter "o." However, in deep orthographies like French, these mappings are far more complex and irregular (e.g., Rey \& Schiller, 2005). First, the same letter can be found in various French graphemes or the same phoneme can be written with different graphemes depending on the word it appears in (i.e., the complexity issue): The grapheme "o" sounds like /o/, but when the letter "o" is present in two-letter grapheme "ou" it is pronounced $/ \mathrm{u} /$, and in the three-letter graphemes "oin" it is pronounced /wẽ/; the phoneme /o/ is spelled "o" in poésie, "ot" in pot, "au" in pauvre, and "eau" in peau. Second, some graphemes map into phonemes in unpredictable ways, and the grapheme-to-phoneme conversion rule will solely depend on the word orthographic context (i.e., the regularity issue): The grapheme "on" is pronounced /õ/ in monstre, montagne, $m$ ontre, and mont, but / / in monsieur; " $\mathrm{s"}$ " is pronounced /s/ in vraisemblable, but /z/ in désuet, maison, and faisant.

\section{In monolinguals}

Behaviorally, cross-linguistic evidence in monolinguals shows that learning to read in deep orthography takes more time and more effort than in a shallow orthography, and that it also exacerbates potential reading difficulties (Landerl et al., 
2013; Landerl, Wimmer, \& Frith, 1997; Schmalz et al., 2015 for a review, see Seymour, Aro, \& Erskine, 2003). To explain these observations, the psychological grain size theory (Ziegler \& Goswami, 2005) proposed that the size of the units on which the lexical representations are built in a language correlates with the depth of the orthography: the deeper the orthography, the larger the units (multiletter clusters, whole words) that will be used for phonological decoding and for building up orthographic lexical representations. The psychological grain size theory is explicitly framed through a phonological view of reading: It proposes that orthographic-specific parameters trigger mechanisms that affect the nature of phonological decoding strategies through the phonological grain size of processing. The psychological grain size theory goes hand in hand with the orthographic-depth hypothesis (Frost, Katz, \& Bentin, 1987), which specifically predicts that readers of deep orthographies will rely more on lexical phonology than will readers in shallow languages.

Accordingly, studies have shown that readers of shallow orthographies rely heavily on sublexical reading strategies (through a reliance on phonemic recoding), whereas readers of deep orthographies should benefit from the use of larger-phonological-grain strategies (e.g., through the access of rimes or the lexicon) to decode the irregular and inconsistent orthographic chunks present in their language (Ellis \& Hooper, 2001; Frost et al., 1987; Katz \& Feldman, 1983; Rau, Moll, Snowling, \& Landerl, 2015; Seymour et al., 2003).

These fundamental differences on the orthographic structures of written alphabetic systems have been linked to functional variations in the underlying brain circuits, despite the fact that the brain circuits for reading are the same across languages. Paulesu et al. (2000) reported that although both Italian (shallow) and English (deep) readers recruited leftlateralized areas of the dorsal and ventral reading pathways, readers of the shallow orthography more strongly activated areas of the dorsal reading pathway than did their deeporthography peers, and readers of the deep orthography showed the opposite pattern (i.e., more activation in the ventral pathway). Therefore, it is reasonable to expect crosslinguistic differences driven by orthographic-depth factors to emerge in the degrees to which certain brain regions are taxed during reading, but also in the dysfunction severity of certain brain regions in relation to others in dyslexia (Hadzibeganovic et al., 2010; Richlan, 2014; but see Paulesu et al., 2001). In line with this idea, greater recruitment of the left inferior parietal lobule may be found in shallow than in deep orthographies (Richlan, 2014) because of the heavier use of phonological decoding strategies in the former writing systems (Ellis \& Hooper, 2001; Goswami, Gombert, \& Fraca de Barrera, 1998; Seymour et al., 2003). Therefore, a dysfunction of this area in dyslexia may be exacerbated in readers of shallow as compared to deep orthographies.

\section{In bilinguals}

Several studies have tried to characterize the impact of orthographic depth on the manifestations of reading skills in both languages of bilingual individuals. Overall, scientific evidence converges toward similar cross-linguistic effects as those reported in monolinguals, and shows that the use of certain reading strategies depends on processing demands imposed by the orthographic structure of the language. Interestingly, these studies evaluate the reading skills of the same participants in two orthographies, and avoid methodological and cultural obstacles faced by cross-linguistic studies that compare different groups of individuals in different countries. Thus, they are very adequate for testing hypotheses related to orthographic depth, provided that the proficiencies and reading levels in the two languages are comparable (Frost, 1994; Wydell \& Butterworth, 1999; Ziegler \& Goswami, 2005).

The reading performance of French-Spanish bilingual children with and without dyslexia was evaluated in both their deep (French) and shallow (Spanish) orthographies (Lallier, Valdois, Lassus-Sangosse, Prado, \& Kandel, 2014). These children were early bilinguals, proficient in their two languages, and had learned to read in both of their languages simultaneously. Bilingual children were more accurate at reading in their shallow orthography than in their deep one, and accuracy deficits of bilingual dyslexic children were more severe in French than Spanish tasks. Moreover, the results pointed toward a preferred small-grain reading strategy in Spanish as compared to French: The bilingual skilled-reader children used both large- and small-grain strategies to read accurately in French, illustrated by the presence of an advantage in reading words over pseudowords. However, both types of items were read as accurately in Spanish, suggesting the use of similar small-grain strategies. In our view, variations in lexicality effects reflect modulations taking place in the lexicon, and the impact of orthographic depth on lexicality effects suggest that bilinguals rely more on the lexicon when they read in their deep than in their shallow orthography. It is worth mentioning here that such results have to be taken with caution, since significant lexical effects on Spanish reading response times were found in both skilled and dyslexic readers. This suggests that children somehow used two different reading strategies in their shallow Spanish orthography. In addition, the lack of lexicality effect on reading accuracy in Spanish might have reflected a ceiling effect, especially so in skilled readers (see Table 2, p. 1182, of Lallier et al., 2014). Therefore, the discrepancy between accuracy and speed measures does not entirely support the hypothesis of modulation in reading grain size by orthographic-depth factors. We will address this point more deeply in the Predictions of the Grain Size Accommodation Hypothesis section. More striking and convincing evidence coming from this same 
study is the presence of accuracy deficits in the dyslexic children on a Spanish task that necessarily required the use of lexical, larger-grain strategies (a lexical orthographic choice task: picking the correct orthographic item between a word and its pseudohomophone-e.g., vaca-baca, llave-yave), but no difficulties on tasks that did not (i.e., text, word, and pseudoword reading). Other work was conducted in bilingual children learning to read simultaneously in alphabetic orthographies with distinct scripts ${ }^{2}$ (English and Hebrew or Persian). Again, these studies drew the same conclusions: bilinguals were generally faster at learning to read in their shallow than their deep orthography (Geva \& Siegel, 2000; Gholamain \& Geva, 1999).

These consistent effects reported in bilinguals are supported by some neuroimaging evidence. Oliver, Carreiras, and Paz-Alonso (2016) assessed two groups of proficient bilinguals sharing the same first language (L1; here, Spanish) but differing in the orthographic depth of their second language (L2) (Basque, shallow; English, deep). When the participants read in their L2, the authors reported a functional co-activation of the left vOT cortex and (1) regions of the ventral pathway for Spanish-English bilinguals, and (2) regions along the dorsal pathway in Spanish-Basque bilinguals. Finally, Buetler and colleagues (2014) elegantly showed that the topography of evoked potentials reflected the use of distinct brain networks for decoding the same pseudowords either in a French (deep) or a German (shallow) context in highly proficient bilinguals. The authors showed that reading a pseudoword in a shallow German context engaged frontal phonological areas involved in sublexical decoding to a greater extent than reading the same pseudoword (by the same bilingual participants) in a deep French context. In addition, pseudoword decoding engaged visuo-attentional parietal areas more strongly in the French than in the German context, suggesting a weaker reliance on sublexical strategies in the deep than in the shallow orthography of the bilingual participants (see also Buetler et al., 2015).

\section{The impact of orthographic depth on the auditory and visual grain size}

What about the impact on cross-linguistic variations in bilinguals on the auditory and visual grain size - that is, when performing tasks that do not engage reading per se? In other words, do cross-linguistic variations also affect auditory phonology and visual attention span skills? Both phonological decoding and whole-word reading strategies require the contribution of auditory and visual processes (Zoubrinetzky, Bielle, \& Valdois, 2014), but via different grain size: The latter

\footnotetext{
${ }^{2}$ Note that this stipulation may have added an additional confounding visual factor in the results.
}

strategy particularly taxes the system's sensitivity to small auditory and visual grains (single-element units), whereas the former would rely on larger grains (multi-element chunks). Consequently, it is reasonable to assume that optimal grain sizes for auditory phonological processing and visual attention span also vary as a function of orthographic depth. For example, shallow grapheme-to-phoneme relationships enhance the awareness of the smallest sounds of language - the phonemes (Hanley, Masterson, Spencer, \& Evans, 2004; Mann \& Wimmer, 2002) - because of the reciprocal positive interactions that exist between phoneme awareness and reading development - that is, the better the reading, the higher the phonemic awareness skills (Bialystok, Majumder, \& Martin, 2003; Castles \& Coltheart, 2004; Morais, Cary, Alegria, \& Bertelson, 1979). Therefore, learning to read in a shallow orthography should promote the development of auditory phonemic processing skills. Orthographic depth should also modulate the size of the visual grain used to parse multi-letter strings (Ans, Carbonnel, \& Valdois, 1998; Perry et al., 2010). In fact, learning to read in a deep orthography such as English might boost the use of large visual grain strategies to overcome difficulties coming from complex and irregular letter-tosound mappings. Graphemes are more likely to be composed of multiple adjacent letters that have to be processed together in order to access the right phoneme. For example, it will be more efficient to memorize the visual chunk "ch" together with the whole word context "yacht" rather than on its own, in order to access its phonology. Therefore, learning to read in a deep orthography should force a wider deployment of visual attention span resources than in shallow orthographies, for which the use of simple letter-to-sound units mapping leads to accurate reading.

\section{In monolinguals}

Cross-linguistic studies in monolingual children confirmed the hypothesis of an advantage for individuals learning to read in shallow orthographies in phonemic processing skills, especially in phonemic awareness (Goswami, Ziegler, \& Richardson, 2005; Patel, Snowling, \& de Jong, 2004). Large-scale cross-linguistic studies have also shown that the contribution of phonological awareness is more important in deep than in shallow orthographies (Vaessen et al., 2010; Ziegler et al., 2010; but see Caravolas, Volín, \& Hulme, 2005), and that the phonological deficits of dyslexic individuals are more severe (Landerl et al., 2013). With regard to neuroimaging evidence, the study of Paulesu et al. (2000) showed higher engagement of phonological brain regions (left superior temporal gyrus) in shallow than in deep orthographies, which could be in accordance with enhanced and facilitated phonological processes in the former orthographies. However, no cross-linguistic differences were highlighted 
regarding the dysfunction of such region for dyslexic readers of shallow than of deep orthographies (Paulesu et al., 2001).

The available cross-linguistic evidence in favor of a larger visual grain in deep than shallow orthographies is scarce. Rau et al. (2015) recently used eye-tracking measures to show different graphemic parsing strategies between English (deep) and German (shallow) children when reading in their native language (see also Rau et al., 2016). These results were interpreted as the necessity of English readers to parse larger orthographic sequences than German readers - that is, a higher number of letters attended during reading. Regarding visual attention span skills, Awadh et al. (2016) conducted a cross-linguistic study in skilled reader adults that did not reveal any difference in the number of visual elements processed simultaneously within a multi-element array between Spanish (shallow) and French (deep). However, visual attention span skills did not correlate with reading skills in Spanish whereas it did in French, suggesting a stronger contribution of the visual attention span to reading in deep orthographies (but see Lallier et al., 2014, in children). Studies quantifying cross-linguistic developmental differences on the brain network supporting visual attention span skills should shed further light on these data.

\section{In bilinguals}

Bilingual studies generally confirm monolingual crosslinguistic findings. Lallier et al. (2014) showed that FrenchSpanish bilingual children exhibited overall better phonemic awareness skills in their shallow- than in their deeporthography language. Similarly, Bialystok et al. (2003) reported that French-English bilingual children performed better in the French than the English language phonological task (French is considered less phonologically complex than English). In contrast, results in dyslexic bilinguals support the absence of any modulation of phonological performance based on orthographic depth (presence of a deficit; Lallier et al., 2014; or absence of deficit: Valdois et al., 2014). It may be the case that bilingual dyslexic children do not benefit from shallow letter-to-sound conversions if an underlying primary phonological deficit causes a deficient decoding procedure. In terms of the visual grain size, de Léon Rodríguez et al. (2015) reported that the location of the first fixation over words produced by early French-German bilingual children was closer to the beginning of words when reading in German (shallow) than when reading in French (deep). These results suggest that bilinguals might distribute their visual attentional resources over words less widely (following a small-grain strategy) in their shallow orthography than in their deep orthography.

Cross-linguistic neuroimaging studies looking at phonological processing in bilinguals offer a less clear picture. For example, Meschyan and Hernandez's (2006) findings in Spanish-English bilinguals support Paulesu et al.'s (2000) study, showing a stronger involvement of phonological areas for shallow than deep orthographies when reading. In contrast, Jamal, Piche, Napoliello, Perfetti, and Eden (2012) reported that proficient bilingual readers of English and Spanish relied more heavily on phonologically related areas in their deep than shallow orthography, because of a greater phonological load imposed by the deep English orthography. These discrepancies may be linked to variations in the degree of overlap between the phonemic repertoires and the grapheme-tophoneme conversion rules of the languages learned by bilinguals. Variations on these phonological dimensions could differentially influence the activation of phonological brain areas in reading and reading-related tasks in bilinguals (Lallier, Acha, \& Carreiras, 2016).

\section{Cross-linguistic transfer in bilinguals: the grain size accommodation hypothesis}

The aforementioned behavioral and neural evidence for orthographic-specific influence on the cognitive and neural reading networks indicates that bilingual individuals can adapt their resources to the orthographic properties of the target language. This reflects the high plasticity and flexibility of the neural and cognitive systems of these individuals. This also suggests that any cross-linguistic transfer happening between the languages of bilinguals should be shaped and driven by these cross-linguistic variations.

How can cross-linguistic transfer in bilinguals be quantified? Classically, evidence for transfer from one language to another has been provided by correlation and regression analyses that measured the relationships between processes in the two languages (e.g., Genesee, Geva, Dressler, \& Kamil, 2006; Saiegh-Haddad \& Geva, 2010). However, these studies alone cannot determine whether this transfer has either positive or negative consequences, whereas comparing the performance of bilinguals against monolinguals or other groups of bilinguals can. This is of critical importance especially when one wants to determine the pros and cons of learning to read in two languages on the development of these skills and their cognitive and neural underpinnings.

Our logic relies on the fact that the simultaneous reading acquisition in two alphabetic writing systems will generate cognitive and neural accommodation ${ }^{3}$ for reading

\footnotetext{
${ }^{3}$ Our hypothesis is in accordance with some aspects of the system accommodation hypothesis (Perfetti \& Liu, 2005; Perfetti et al., 2007) that has been proposed to explain sequential bilingual reading acquisition in different writing systems (such as English and Korean), mostly varying in both their orthography (alphabetic vs. syllabic or logographic) and scripts (visual appearance of the writing system). The accommodation hypothesis predicts that when reading is acquired in a new writing system, L2 reading procedures (and neural underpinnings) should be assimilated to those used in the L1. However, when the writing systems are dissimilar enough (such as Chinese and English), the reading network is assumed to accommodate to develop the new neural and cognitive resources necessary to read in the $\mathrm{L} 2$.
} 
development that will further depend on deviations between the two languages in their orthographic depth. In particular, reading acquisition in two languages should prompt the use of a grain size that results from this accommodation process. We hypothesize that a cross-linguistic blending occurs between the preferred grain sizes triggered by different orthographies. In other words, the preferred resulting reading strategies (i.e., serial-decoding-like or whole-word lexical-reading-like) and cognitive resources (auditory phonology and visual attention span) depend on a hybrid grain size between those that monolinguals would use in similar situations (see Fig. 2).

\section{Predictions of the grain size accommodation hypothesis}

Importantly, the grain size accommodation hypothesis allows us to a priori predict the direction of group differences that should be observed, on the basis of the orthographic properties of the language(s) learned. We predict that bilingual readers who acquire reading in a deep in addition to a shallow orthography should rely on smaller grains (e.g., overreliance on sublexical strategies and reduced lexical effects in reading) in their deep orthography than would monolinguals in this same deep language. Conversely, the same bilingual readers should use larger grains in their shallow orthography (e.g., greater lexical effects in reading and wider visual attention span deployment) than would monolinguals reading in this same shallow orthography.

These predictions can be tested through the use of classical tasks and between-group designs involving the comparison of monolinguals versus bilinguals on their common language (i.e., French-Spanish bilinguals vs. Spanish monolinguals in Spanish), or of a bilingual group versus another bilingual group on their common language (i.e., Spanish-Basque bilinguals vs. Spanish-French bilinguals in Spanish). Below, we propose possible experiments that would allow for testing our predictions in bilinguals with regard to the grain size used in reading, the auditory phonological grain size, and the visual grain size.

First, we propose that the size of lexical effects in naming or lexical decision tasks (speed and/or accuracy) could indicate the relative difference between the preferred grain size used for reading lexical and nonlexical orthographic items (see Lallier et al., 2016; Lallier et al., 2014). For example, larger lexical effects for French-Spanish bilinguals than for Spanish monolinguals in Spanish should reflect a greater reliance on the lexical procedure (and on larger grains) in the bilingual group, because of the accommodation processes resulting from knowing how to read in the deep French orthography. Following the same reasoning, smaller lexical effects for Spanish-Basque bilinguals than for Spanish-French bilinguals in Spanish would be expected. These specific predictions should also be assessed through neuroimaging designs: In particular, the effective connectivity between the regions of the reading network should be a good estimate of the degree of reliance on the dorsal (sublexical, small-grain) and the ventral (lexical, large-grain) reading pathways while reading different types of items (e.g., see the method used by Levy et al., 2009).

It is important to keep in mind that orthographic-depth modulations of lexical effects in reading might not necessarily be the same for accuracy and speed measures. For example, Lallier et al. (2014) in Spanish-French bilinguals reported a lexical effect on reading speed but not on reading accuracy in Spanish whereas similar lexical effects were found on speed and accuracy in French. Interestingly, reading speed was strongly linked to visual attention span skills whereas reading accuracy was only linked to phonemic awareness skills (see Figs. 1, 2, 3, and 4 in Lallier et al., 2014). We argue that such
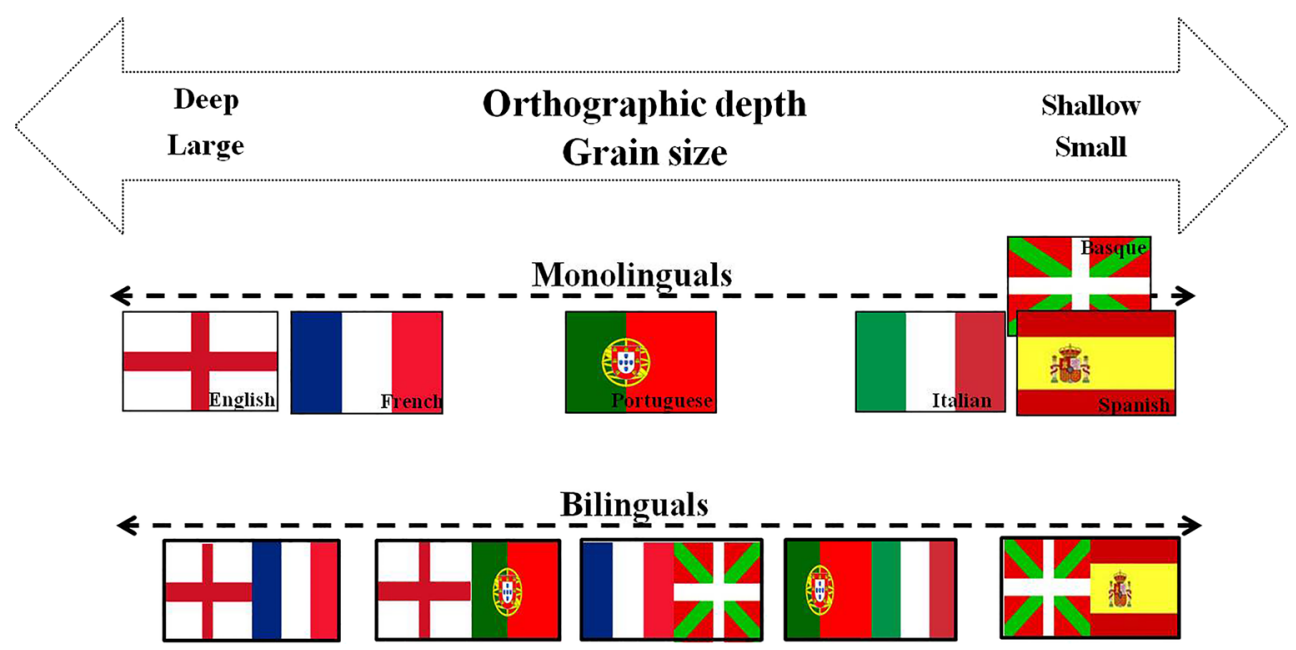

Fig. 2 Illustration of the grain size accommodation hypothesis, based on orthographic-depth factors in simultaneous bilinguals reading in two alphabetic orthographies. The grain size used by bilingual readers would correspond to a hybrid grain size that results from the monolingual reading strategies prompted by these orthographies 


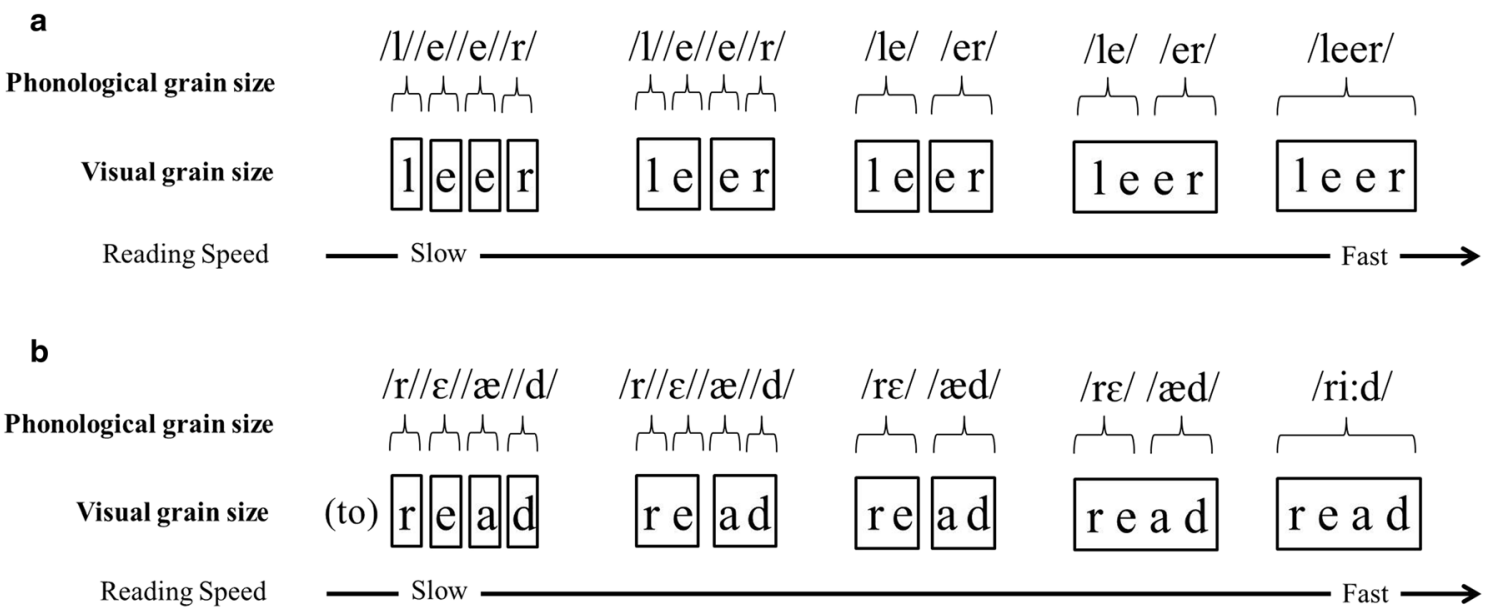

Fig. 3 Illustration of a nonexhaustive series of possible combinations between the visual grain size (size of the black squares) and the phonological grain (size of the braces) accessed from print, by individuals reading the words (a) "leer" in Spanish and (b) "(to) read" in English. From left to right: Visual and phonological small-grain combinations simulate decoding-like strategies, whereas large-grain combinations simulate lexical reading. The visual grain size determines

findings support the use of different visual and phonological grain sizes (preferentially affecting reading speed and accuracy, respectively) in the same individuals when reading in their shallow orthography. Figure 3 illustrates how orthographicdepth factors may partly determine whether large-visualgrain strategies are accompanied by large-phonological-grain strategies and may modulate lexical effects on speed and accuracy measures in the same individuals.

It has been previously shown that, for both shallow and deep orthographies, the greater the visual attention span skills, the faster the reading speed (Lallier et al., 2014; Lobier, Dubois, \& Valdois, 2013), showing that when several letters are identified simultaneously in one visual attentional capture, the following reading computations are speeded up (e.g., phonological access from print). Therefore, lexical effects on reading speed may be expected across orthographies (see Fig. 3). We predict a different picture for reading accuracy. In shallow orthographies (Fig. 3a), letters identified simultaneously through a large visual grain could be converted through a phoneme-by-phoneme strategy or through access to rimes or phonological lexical representations. In fact, the use of any phonological grain size would similarly lead to accurate words and pseudoword reading, regardless of the visual grain size used: In this case, the absence of a lexical effect on accuracy would be predicted. In deep orthographies (Fig. 3b), the use of large phonological grains should often accompany the use of large visual grains, because in most cases, accessing rimes or whole-word phonological units would constrain reading accuracy. In that case, lexical effects on both speed and accuracy would be expected (see Fig. 3b). Overall, to avoid reporting inconsistent findings across studies reading speed in both the (a) shallow and (b) deep orthographies, whereas the phonological grain size determines reading accuracy in the deep orthography only. In Spanish, any phonological grain size strategies lead to accurate reading if the correct grapheme-to-phoneme conversion rules are applied. In English, the use of both large visual and phonological grains is necessary to read accurately and solve complex grapheme-tophoneme mappings (e.g., the rightmost situation in panel b)

(e.g., Schmalz, Robidoux, Castles, Coltheart, \& Marinus, 2017), future studies attempting to test our predictions in bilinguals through lexical effects on reading should systematically take into account both accuracy and speed measures in relation to phonological and visual grain sizes.

Second, predictions for the auditory phonological grain size could easily be tested with tasks tapping into phonemic

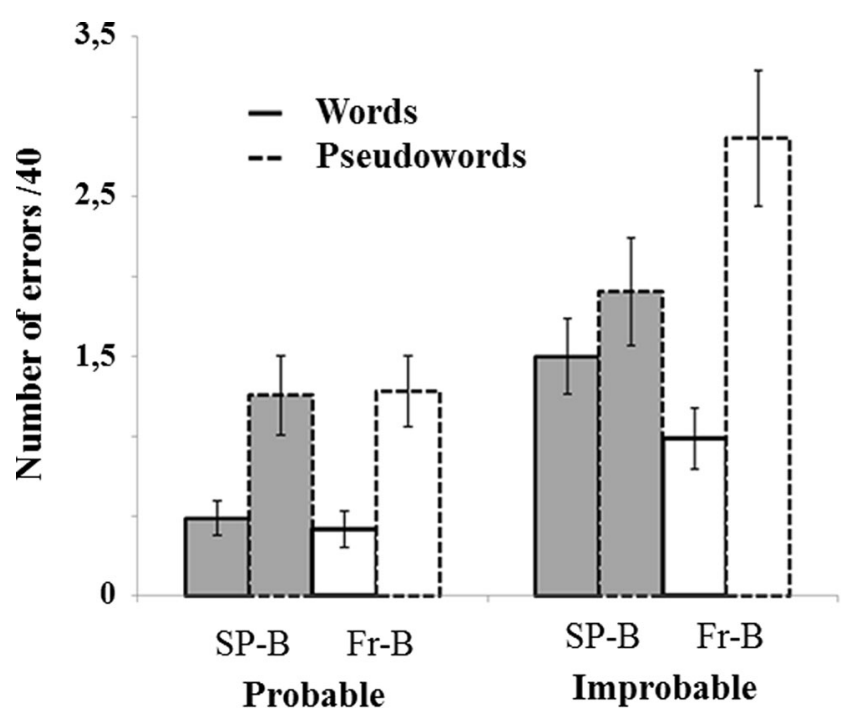

Fig. 4 Performance on Basque single-item reading in Spanish-Basque bilinguals (gray bars; SP-B) and French-Basque bilinguals (white bars; FR-B). Standard error bars are depicted. From "Cross-Linguistic Interactions Influence Reading Development in Bilinguals: A Comparison Between Early Balanced French-Basque and SpanishBasque Bilingual Children," by M. Lallier, J. Acha, \& M. Carreiras, 2016, Developmental Science, 19, p. 83. Copyright 2015 by John Wiley \& Sons. Reprinted with permission 
awareness, such as deleting the first phoneme of pseudowords presented auditorily or segmenting pseudowords into their constituent phonemes. For example, we expect larger phonological-grain-size strategies to result in a greater number of deletion errors such as first-syllable or onset deletions (i.e., $/ \mathrm{platu} /$ being segmented as $/ \mathrm{pla} / / \mathrm{tu} /$ or $/ \mathrm{pl} / / \mathrm{atu} /$ instead of $/ \mathrm{p} / /$ latu/). At the brain level, a stronger bias toward left auditory cortex may be found in response to phonological items among individuals highly sensitive to phonemic details than among individuals who rely more on larger phonological units such as syllables (Lizarazu et al., 2015; Molinaro, Lizarazu, Lallier, Bourguignon, \& Carreiras, 2016; Poeppel, 2003).

Third, accommodation processes in visual grain size could be measured through the visual attention span skills of participants: A wider visual attention span deployment (i.e., a higher numbers of visual elements being identified simultaneously) and a stronger contribution of these skills to reading would be expected if individuals rely on large-visual-grain strategies. At the brain level, stronger engagement of the superior parietal lobule while performing reading or reading-related tasks should reflect higher visual attention span skills demands and the use of larger visual-grain strategies. Finally, eye movements could also be informative (see de León Rodríguez et al., 2015). For example, the distance between the location of the first fixation over words or pseudowords and the beginning of the items might be another index of the size of the visual grain used, such that the farther the first fixation lands from the beginnings of items, the larger the visual grain used.

\section{Behavioral and event-related brain potential (ERP) evidence supporting the grain size accommodation hypothesis so far}

In this section we present studies conducted on simultaneous bilingual populations that directly support the grain size accommodation hypothesis (see Fig. 2). These studies have compared either different groups of bilinguals against each other or bilinguals against monolinguals in the same language, in order to assess whether bilingualism per se has positive outcomes on reading and reading-related skills in alphabetic languages, or whether this depends on the specificities of the orthographies of the two languages.

In a first study, Lallier et al. (2016) evaluated bilingual children attending Grades 2 and 5 in the French-Basque bilingual region and the Spanish-Basque bilingual region of the Basque Country. A series of tasks were administered in Basque (a shallow orthography) to all children including a phonemic deletion task, an adaptation of the partial report task (measuring the visual attention span), and a list of Basque word and pseudoword reading. Importantly, all children were matched for their linguistic proficiency and use of Basque and of the other language (French or Spanish). The four bilingual groups were characterized as early proficient simultaneous bilinguals. Therefore, evaluating these groups offered us an exceptional opportunity to quantify the impact of the orthographic properties of a deep and a shallow orthography on reading acquisition in another orthography (Basque). The results showed that first, the Spanish-Basque bilinguals made fewer errors when reading Basque pseudowords than the French-Basque bilinguals independently of the grade. This group difference was observed only in the most difficult condition - that is, on improbable pseudowords that did not respect Basque orthotactics (see Fig. 4). The authors proposed that the deeper encoding of the links between letters and sounds in Spanish-Basque bilinguals (who know two shallow orthographies) sharpened small-grain decoding strategies in Basque. Moreover, auditory phonemic processing was also enhanced in these same children, since the Spanish-Basque bilinguals outperformed their French-speaking peers on the most difficult condition of the Basque phonemic deletion task - deleting the first phoneme of a CCV phonological cluster. Therefore, as hypothesized, different grain sizes in the two groups were automatically used, in particular in difficult situations of Basque processing. Finally, the results for visual attention span skills suggested that fewer visual units from a five-letter array presented briefly $(200 \mathrm{~ms})$ were salient for Spanish-speaking children in Grade 2 than for their Frenchspeaking peers. This difference disappeared at Grade 5. As predicted, this illustrated that learning to read in a deep in addition to a shallow orthography boosts from early on the homogeneous deployment of visual attention over orthographic strings. This hypothesis was also supported by the fact that at both grade levels, French-Basque bilinguals demonstrated a word familiarity advantage over pseudowords (potentially stemming from the use of large-grain strategies) on Basque reading accuracy, whereas Spanish-Basque bilinguals read both types of items with similar accuracies. Moreover, this was observed only in challenging reading - that is, in improbable words and pseudowords that did not respect Basque orthotactic rules (see Fig. 4).

At this stage, it is important to point out that the interpretation of the data from Lallier et al. (2016) should be presented with caution: Spanish and Basque share most of their phonemic categories, as well as their grapheme-to-phoneme mapping rules whereas French and Basque do not. To rule out any phonological distance effect on the results obtained, it is important to test and confirm our hypothesis in bilinguals knowing one deep and one shallow orthographies that overlap minimally in terms of phonemic repertoires, and grapheme-tophoneme conversion rules. This is the case of Welsh and English. Lallier, Carreiras, Tainturier, Savill, and Thierry (2013) asked English monolingual and early Welsh (shallow)-English bilingual reader adults to report whether or not a target letter displayed at fixation was present in either a nonword (consonant string) or an English word presented immediately before (for $180 \mathrm{~ms}$ ). ERPs were simultaneously 
recorded. For word and nonword probe trials, behavioral performance was overall unaffected by target letter position in the probe (being at ceiling for word probes), suggesting similarly orthographic encoding in the two groups. In contrast, the amplitude of ERPs locked to the target letters (P3b: 340-570 ms post-target-onset) were differently modulated by the position of the target letter in words and nonwords between bilinguals and monolinguals. P3b results show that bilinguals who learned to read simultaneously in a deep and in a shallow orthography encoded English orthographic information presented to the right of fixation more poorly than did monolinguals, again reflecting a narrower mode of visual attention distribution, potentially due to the acquisition of a shallow orthography. Importantly, this study also suggests that group effects that may be hidden by ceiling effects observed behaviorally can be revealed by using more sensitive measures, such as ERPs.

The results of the last two studies support the grain size accommodation hypothesis in bilingual groups whose languages share or not their phonemic repertoires and grapheme-to-phoneme conversion rules. However, they cannot address the question as to whether similar effects would persist when the languages of bilinguals do not share the same alphabet. In fact, one may hypothesize that having to learn two scripts and two sets of visual symbols may override the manifestations of grain size accommodation. The study of Bialystok, Luk, and Kwan (2005) suggests the opposite finding. These authors compared the decoding and phonological awareness skills of groups of Grade 1 children speaking and learning to read in English and another shallow alphabetic language that could either share the same script as English (Spanish) or not (Hebrew). Importantly, these two bilingual groups were also compared to a group of monolingual English children. The authors showed that children who had learnt a shallow orthography in addition to English outperformed their English monolingual peers on phonemic awareness (phoneme counting task). In the case of pseudoword decoding, the authors showed that the Hebrew-English bilinguals significantly outperformed their English monolingual peers (note that the Spanish-speaking children exhibited better scores than the English monolinguals although this difference was not significant). Overall, these results speaks in favor of a phonological processing advantage (i.e., on phonemic awareness and on phonological decoding) for beginner bilingual readers knowing a shallow orthography in addition to English, regardless of whether the two languages share the same alphabet or not.

Taken together, these studies shed light on how crosslinguistic transfer driven by orthography-specific factors constrains both the phonological and visual grain size underlying oral and written language processing in bilinguals. In particular, learning to read in a shallow in addition to a deep orthography may result in an advantage in the development of phonemic awareness that would help overcome phonologically challenging processing situations. However, this may still present a slight disadvantage, relative to learning to read only in a deep orthography, when the reading situation requires spreading visual attention resources broadly over the letter string. Would these effects appear similarly in the symptoms of bilingual dyslexia? Lallier, Barr, Thierry, Carreiras, and Tainturier (under review) offer preliminary hints as to how bilingualism and cross-linguistic transfer can affect positively or negatively the manifestations of reading disorders, depending on orthographic-specific features of the language learned (see also Abu-Rabia \& Siegel, 2002; Da Fontura \& Siegel, 1995). The authors assessed a group of 15 Welsh-English bilingual adults with dyslexia and a group of 15 English monolingual adults with dyslexia, and compared their performance on words and pseudoword reading, as well as visual attention span and phonemic awareness in English, to a group of 15 agematched skilled monolingual readers and a group of 15 agematched skilled bilingual readers. Importantly, the two dyslexic groups showed similar global poor reading level in English. The results revealed a benefit of learning to read in a shallow orthography (Welsh) in addition to English on the manifestations of dyslexia only on literacy tasks engaging a high degree of phonological processing, such as spelling. Welsh-English dyslexic bilinguals also exhibited weaker lexicality effects than did English monolingual dyslexic participants, which might eventually have affected the buildup of lexical orthographic knowledge. Again, this data suggests that learning to read in a shallow orthography in addition to English might narrow down the grain size for performing literacy tasks in English.

\section{Challenges faced by the grain size accommodation hypothesis}

Factors independent of orthographic depth (and of the overlap in phonological repertoires and scripts) might modulate which grain size may be preferred or optimal relative to others.

For example, small-grain strategies are extremely important for acquiring reading at early developmental stages, whereas large-grain strategies might be equally important across development (Bosse \& Valdois, 2009; Ziegler et al., 2013). Moreover, item familiarity may impose some constraints on the grain size used to read: Unfamiliar and infrequent words are likely to engage decoding and small-grain strategies, whereas reading familiar and frequent words is prone to rely on lexical and large-grain strategies. We expect cross-linguistic transfer based on orthographic-depth factors to also undertake modulations driven by the processing demands of the reading situation itself. This is illustrated in Fig. 5. In particular, longitudinal studies in bilinguals before and after learning to read should be highly valuable to determining whether and how much cross-linguistic transfer and grain size accommodation processes vary across development, while taking into account the nature of the items read. 


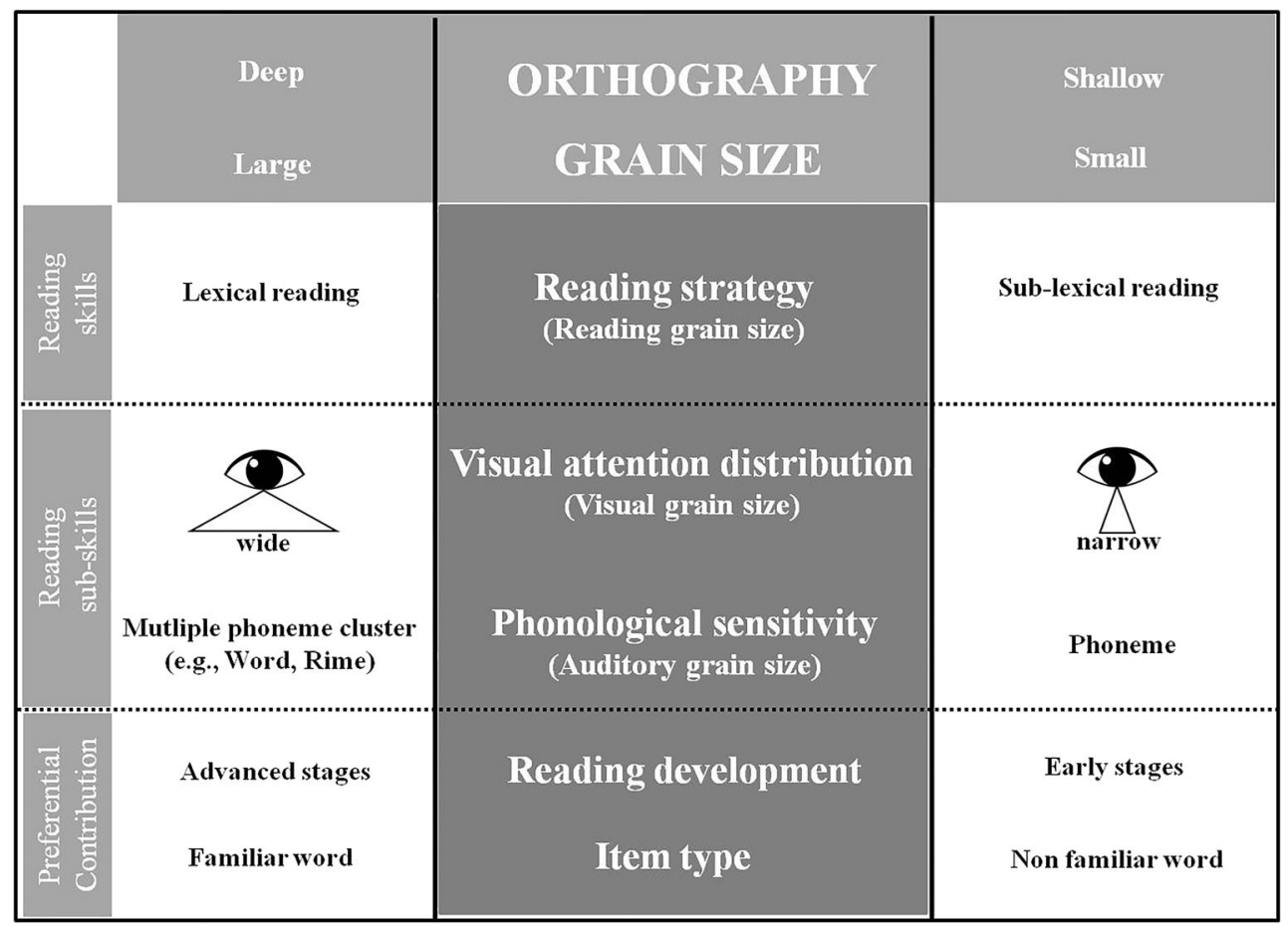

Fig. 5 Illustration of the orthographic-depth effects on the grain size used for performing reading tasks (i.e., reading skills) and reading-related cognitive tasks (i.e., reading subskills), as well as the reading situations in which these orthographic-specific variations might contribute preferentially

In addition to the level of reading expertise (see Fig. 5), grain size accommodation processes may also fluctuate depending on linguistic proficiency (de León Rodríguez et al., 2016). We foresee that the development of hybrid strategies described in the presentation of our hypothesis may especially thrive when reading is simultaneously acquired in two orthographies (i.e., early simultaneous bilinguals). In this particular case, immature cognitive and neural reading networks would be ready to integrate and accommodate to all linguistic orthographic experiences, with equivalent predispositions for deep and shallow inputs. This would result in reading strategies being generated and self-taught from both deep and shallow orthographic environments. The studies presented here were conducted in early highly proficient simultaneous bilinguals. Future studies should also evaluate the present framework in late low proficient sequential bilinguals in order to refine the grain size accommodation hypothesis.

Last (but not least), we hope that the scope of the present hypothesis will eventually broaden to bilingual reading acquisition in nonalphabetic languages, as well as in individuals who master more than two languages, since a large proportion of the worldwide population falls within these categories.

\section{Conclusions}

The data presented throughout this article point toward the existence of orthographic-specific influences and cross-linguistic interactions on reading in bilinguals learning to read (children) or having learned to read (adults) in two alphabetic orthographies simultaneously. We report consistent results on the nature of the modulations of cross-linguistic transfer in both typical and atypical reading development in various groups of bilinguals. More particularly, these results show that the phonological and visual grain sizes used for reading and performing reading-related tasks are subject to accommodation processes driven by the orthographic properties of both languages of bilinguals. Importantly, we identified a number of factors that might influence the outcomes of studies assessing the grain size accommodation hypothesis in bilinguals-for instance, the scripts of and phonological distance between the two languages of bilinguals, language proficiency, developmental stage, and the type of item presented. Future studies will be needed to determine the behavioral and neural (structural and functional) fingerprints of crosslinguistic accommodation based on orthographic depth, and their modulation by these additional factors. Finally, since orthographic depth prompts the use of distinct cognitive strategies for reaching similar goals (i.e., reading), some specific language pairs may (more than others) offer the opportunity to compensate for reading and cognitive difficulties in bilingual dyslexic individuals. Therefore, practical questions are open as to the power of positive cross-linguistic transfer in bilingualism for 
developing evidence-based reading teaching methods and remediation programs for bilinguals learning to read in two orthographies simultaneously.

Author Note This work was supported by the European commission (BILITERACY- SH4, ERC-2011-ADG) and the Ministry of Economy and Competitiveness, Madrid, Spain (Grant Nos. PSI20153653383P to M.L., PSI20153673533R to M.C., and SEV3201530490 to the Basque Center on Brain and Language Cognition).

\section{References}

Abu-Rabia, S., \& Siegel, L. S. (2002). Reading, syntactic, orthographic, and working memory skills of bilingual Arabic-English speaking Canadian children. Journal of Psycholinguistic Research, 31, 661678.

Ans, B., Carbonnel, S., \& Valdois, S. (1998). A connectionist multipletrace memory model for polysyllabic word reading. Psychological Review, 105, 678-723. doi:10.1037/0033-295X.105.4.678

Astafiev, S. V., Shulman, G. L., \& Corbetta, M. (2006). Visuospatial reorienting signals in the human temporo-parietal junction are independent of response selection. European Journal of Neuroscience, 23, 591-596.

Awadh, F. H., Phénix, T., Antzaka, A., Lallier, M., Carreiras, M., \& Valdois, S. (2016). Cross-language modulation of visual attention span: An Arabic-French-Spanish comparison in skilled adult readers. Frontiers in psychology, 7, 307. doi:10.3389/fpsyg.2016. 00307.

Bialystok, E., Luk, G., \& Kwan, E. (2005). Bilingualism, biliteracy, and learning to read: Interactions among languages and writing systems. Scientific Studies of Reading, 9, 43-61.

Bialystok, E., Majumder, S., \& Martin, M. M. (2003). Developing phonological awareness: Is there a bilingual advantage? Applied Psycholinguistics, 24, 27-44.

Boets, B., de Beeck, H. P. O., Vandermosten, M., Scott, S. K., Gillebert, C. R., Mantini, D.,...Ghesquière, P. (2013). Intact but less accessible phonetic representations in adults with dyslexia. Science, 342, $1251-1254$

Bosse, M.-L., Chaves, N., Largy, P., \& Valdois, S. (2015). Orthographic learning during reading: The role of whole-word visual processing. Journal of Research in Reading, 38, 141-158. doi:10.1111/j.14679817.2012.01551.x

Bosse, M.-L., Tainturier, M. J., \& Valdois, S. (2007). Developmental dyslexia: The visual attention span deficit hypothesis. Cognition, 104, 198-230.

Bosse, M.-L., \& Valdois, S. (2009). Influence of the visual attention span on child reading performance: A cross-sectional study. Journal of Research in Reading, 32, 230-253. doi:10.1111/j.1467-9817.2008. 01387.x

Brem, S., Bach, S., Kucian, K., Guttorm, T. K., Martin, E., Lyytinen, H., ...Richardson, U. (2010). Brain sensitivity to print emerges when children learn letter-speech sound correspondences. Proceedings of the National Academy of Sciences, 107, 7939-7944.

Buetler, K. A., de León Rodríguez, D., Laganaro, M., Müri, R., Nyffeler, T., Spierer, L., \& Annoni, J. M. (2015). Balanced bilinguals favor lexical processing in their opaque language and conversion system in their shallow language. Brain and Language, 150, 166-176.

Buetler, K. A., de León Rodríguez, D., Laganaro, M., Müri, R., Spierer, L., \& Annoni, J. M. (2014). Language context modulates reading route: An electrical neuroimaging study. Frontiers in Human Neuroscience, 8, 83. doi:10.3389/fnhum.2014.00083
Cao, F., Bitan, T., \& Booth, J. R. (2008). Effective brain connectivity in children with reading difficulties during phonological processing. Brain and Language, 107, 91-101.

Caravolas, M., Volín, J., \& Hulme, C. (2005). Phoneme awareness is a key component of alphabetic literacy skills in consistent and inconsistent orthographies: Evidence from Czech and English children. Journal of Experimental Child Psychology, 92, 107-139.

Carreiras, M., Armstrong, B. C., Perea, M., \& Frost, R. (2014). The what, when, where, and how of visual word recognition. Trends in Cognitive Sciences, 18, 90-98. doi:10.1016/j.tics.2013.11.005

Carreiras, M., Quiñones, I., Hernández-Cabrera, J. A., \& Duñabeitia, J. A. (2015). Orthographic coding: Brain activation for letters, symbols, and digits. Cerebral Cortex, 25, 4748-4760. doi:10.1093/cercor/ bhu 163

Castles, A., \& Coltheart, M. (2004). Is there a causal link from phonological awareness to success in learning to read? Cognition, 91, 77-111.

Cohen, L., Dehaene, S., Vinckier, F., Jobert, A., \& Montavont, A. (2008). Reading normal and degraded words: Contribution of the dorsal and ventral visual pathways. NeuroImage, 40, 353-366.

Cohen, L., Lehéricy, S., Chochon, F., Lemer, C., Rivaud, S., \& Dehaene, S. (2002). Language-specific tuning of visual cortex? Functional properties of the visual word form area. Brain, 125, 1054-1069.

Corbetta, M., \& Shulman, G. L. (2002). Control of goal-directed and stimulus-driven attention in the brain. Nature Reviews Neuroscience, 3, 201-215.

Da Fontoura, H. A., \& Siegel, L. S. (1995). Reading, syntactic, and working memory skills of bilingual Portuguese-English Canadian children. Reading and Writing, 7, 139-153.

de León Rodríguez, D., Buetler, K. A., Eggenberger, N., Laganaro, M., Nyffeler, T., Annoni, J. M., \& Müri, R. M. (2016). The impact of language opacity and proficiency on reading strategies in bilinguals: An eye movement study. Frontiers in Psychology, 7, 649. doi:10. 3389/fpsyg.2016.00649

de León Rodriguez, D., Buetler, K. A., Eggenberger, N., Preisig, B. C., Schumacher, R., Laganaro, M.,...Müri, R. M. (2015). The modulation of reading strategies by language opacity in early bilinguals: An eye movement study. Bilingualism: Language and Cognition, 19, 567-577.

Ellis, N. C., \& Hooper, A. M. (2001). It is easier to learn to read in Welsh than in English: Effects of orthographic transparency demonstrated using frequency-matched cross-linguistic reading tests. Applied Psycholinguistics, 22, 571-599.

Facoetti, A., Zorzi, M., Cestnick, L., Lorusso, M. L., Molteni, M., Paganoni, P.,...Mascetti, G. G. (2006). The relationship between visuo-spatial attention and nonword reading in developmental dyslexia. Cognitive Neuropsychology, 23, 841-855. doi:10.1080/ 02643290500483090

Franceschini, S., Gori, S., Ruffino, M., Viola, S., Molteni, M., \& Facoetti, A. (2013). Action video games make dyslexic children read better. Current Biology, 23(6), 462-466.

Frost, R. (1994). Prelexical and postlexical strategies in reading: Evidence from a deep and a shallow orthography. Journal of Experimental Psychology: Learning, Memory, and Cognition, 20, 116-129. doi: 10.1037/0278-7393.20.1.116

Frost, R., Katz, L., \& Bentin, S. (1987). Strategies for visual word recognition and orthographical depth: A multilingual comparison. Journal of Experimental Psychology: Human Perception and Performance, 13, 104-115. doi:10.1037/0096-1523.13.1.104

Genesee, F., Geva, E., Dressler, C., \& Kamil, M. (2006). Synthesis: Cross-linguistic relationships. In D. August \& T. Shanahan (Eds.), Developing literacy in second-language learners: Report of the National Literacy Panel on language-minority children and youth (pp. 153-174). Mahwah, NJ: Erlbaum.

Geva, E., \& Siegel, L. S. (2000). Orthographic and cognitive factors in the concurrent development of basic reading skills in two languages. Reading and Writing, 12, 1-30. 
Gholamain, M., \& Geva, E. (1999). Orthographic and cognitive factors in the concurrent development of basic reading skills in English and Persian. Language Learning, 49, 183-217.

Goswami, U. (2015). Sensory theories of developmental dyslexia: Three challenges for research. Nature Reviews Neuroscience, 16, 43-54.

Goswami, U., Gombert, J. E., \& Fraca de Barrera, L. (1998). Children's orthographic representations and linguistic transparency: Nonsense word reading in English, French, and Spanish. Applied Psycholinguistics, 19, 19-52. doi:10.1017/S0142716400010560

Goswami, U., Ziegler, J. C., \& Richardson, U. (2005). The effects of spelling consistency on phonological awareness: A comparison of English and German. Journal of Experimental Child Psychology, 92, 345-365.

Grainger, J., \& Ziegler, J. C. (2011). A dual-route approach to orthographic processing. Frontiers in Psychology, 2, 54. doi:10.3389/fpsyg. 2011.00054

Hadzibeganovic, T., van den Noort, M., Bosch, P., Perc, M., van Kralingen, R., Mondt, K., \& Coltheart, M. (2010). Cross-linguistic neuroimaging and dyslexia: A critical view. Cortex, 46, 1312-1316.

Hanley, R., Masterson, J., Spencer, L., \& Evans, D. (2004). How long do the advantages of learning to read a transparent orthography last? An investigation of the reading skills and reading impairment of Welsh children at 10 years of age. Quarterly Journal of Experimental Psychology, 57A, 1393-1410.

Hari, R., \& Renvall, H. (2001). Impaired processing of rapid stimulus sequences in dyslexia. Trends in Cognitive Sciences, 5, 525-532.

Jamal, N. I., Piche, A. W., Napoliello, E. M., Perfetti, C. A., \& Eden, G. F. (2012). Neural basis of single-word reading in Spanish-English bilinguals. Human Brain Mapping, 33, 235-245. doi:10.1002/hbm. 21208

Jobard, G., Crivello, F., \& Tzourio-Mazoyer, N. (2003). Evaluation of the dual route theory of reading: A metanalysis of 35 neuroimaging studies. NeuroImage, 20, 693-672.

Katz, L., \& Feldman, L. B. (1983). Relation between pronunciation and recognition of printed words in deep and shallow orthographies. Journal of Experimental Psychology: Learning, Memory, and Cognition, 9, 157.

Lallier, M., Acha, J., \& Carreiras, M. (2016). Cross-linguistic interactions influence reading development in bilinguals: A comparison between early balanced French-Basque and Spanish-Basque bilingual children. Developmental Science, 19, 76-89. doi:10.1111/desc.12290

Lallier, M., Carreiras, M., Tainturier, M. J., Savill, N., \& Thierry, G. (2013). Orthographic transparency modulates the grain size of orthographic processing: Behavioral and ERP evidence from bilingualism. Brain Research, 1505, 47-60. doi:10.1016/j.brainres. 2013.02.018

Lallier, M., Donnadieu, S., Berger, C., \& Valdois, S. (2010). A case study of developmental phonological dyslexia: Is the attentional deficit in the perception of rapid stimuli sequences amodal? Cortex, 46, 231241.

Lallier, M., \& Valdois, S. (2012). Sequential versus simultaneous processing deficits in developmental dyslexia. In T. N. Wydell \& L. FernPollak (Eds.), Dyslexia: A comprehensive and international approach (pp. 73-108). New York, NY: InTech.

Lallier, M., Valdois, S., Lassus-Sangosse, D., Prado, C., \& Kandel, S. (2014). Impact of orthographic transparency on typical and atypical reading development: Evidence in French-Spanish bilingual children. Research in Developmental Disabilities, 35, 1177-1190.

Landerl, K., Ramus, F., Moll, K., Lyytinen, H., Leppänen, P. H., Lohvansuu, K.,... Schulte-Körne, G. (2013). Predictors of developmental dyslexia in European orthographies with varying complexity. Journal of Child Psychology and Psychiatry, 54, 686-694.

Landerl, K., Wimmer, H., \& Frith, U. (1997). The impact of orthographic consistency on dyslexia: A German-English comparison. Cognition, 63, 315-334.
Lassus-Sangosse, D., N'Guyen-Morel, M. A., \& Valdois, S. (2008). Sequential or simultaneous visual processing deficit in developmental dyslexia? Vision Research, 48, 979-988.

Levy, J., Pernet, C., Treserras, S., Boulanouar, K., Aubry, F., Démonet, J. F., \& Celsis, P. (2009). Testing for the dual-route cascade reading model in the brain: an fMRI effective connectivity account of an efficient reading style. PLoS One, 4(8), e6675.

Lizarazu, M., Lallier, M., Molinaro, N., Bourguignon, M., Paz Alonso, P. M., Lerma Usabiaga, G., \& Carreiras, M. (2015). Developmental evaluation of atypical auditory sampling in dyslexia: Functional and structural evidence. Human Brain Mapping, 36, 4986-5002.

Lobier, M., Dubois, M., \& Valdois, S. (2013). The role of visual processing speed in reading speed development. PLOS ONE, 8, e58097. doi: 10.1371/journal.pone.0058097

Lobier, M., Peyrin, C., Le Bas, J. F., \& Valdois, S. (2012). Preorthographic character string processing and parietal cortex: A role for visual attention in reading? Neuropsychologia, 50, 2195-2204.

Lobier, M., Zoubrinetzky, R., \& Valdois, S. (2012). The visual attention span deficit in dyslexia is visual and not verbal. Cortex, 48, 768773.

Mann, V., \& Wimmer, H. (2002). Phoneme awareness and pathways into literacy: A comparison of German and American children. Reading and Writing, 15, 653-682.

Mars, R. B., Sallet, J., Schüffelgen, U., Jbabdi, S., Toni, I., \& Rushworth, M. F. (2012). Connectivity-based subdivisions of the human right "temporoparietal junction area": Evidence for different areas participating in different cortical networks. Cerebral Cortex, 22, 1894 1903

Melby-Lervåg, M., Lyster, S. A. H., \& Hulme, C. (2012). Phonological skills and their role in learning to read: A meta-analytic review. Psychological Bulletin, 138, 322-352. doi:10.1037/a0026744

Meschyan, G., \& Hernandez, A. E. (2006). Impact of language proficiency and orthographic transparency on bilingual word reading: An fMRI investigation. NeuroImage, 29, 1135-1140.

Molinaro, N., Lizarazu, M., Lallier, M., Bourguignon, M., \& Carreiras, M. (2016). Out-of-synchrony speech entrainment in developmental dyslexia. Human Brain Mapping, 37, 2767-2783. doi:10.1002/ hbm. 23206

Morais, J., Cary, L., Alegria, J., \& Bertelson, P. (1979). Does awareness of speech as a sequence of phones arise spontaneously? Cognition, 7, 323-331.

Oliver, M., Carreiras, M., \& Paz-Alonso, P. M. (2016). Functional dynamics of dorsal and ventral reading networks in bilinguals. Cerebral Cortex, 1-13. doi:10.1093/cercor/bhw310

Onochie-Quintanilla, E., Defior, S., \& Simpson, I. C. (2017). Visual multi-element processing as a pre-reading predictor of decoding skill. Journal of Memory and Language, 94, 134-148.

Patel, T. K., Snowling, M. J., \& de Jong, P. F. (2004). A cross-linguistic comparison of children learning to read in English and Dutch. Journal of Educational Psychology, 96, 785-797. doi:10.1037/ 0022-0663.96.4.785

Paulesu, E., Démonet, J. F., Fazio, F., McCrory, E., Chanoine, V., Brunswick, N.,...Frith, U. (2001). Dyslexia: Cultural diversity and biological unity. Science, 291, 2165-2167.

Paulesu, E., McCrory, E., Fazio, F., Menoncello, L., Brunswick, N., Cappa, S. F.,..., Frith, U. (2000). A cultural effect on brain function. Nature Neuroscience, 3, 91-96.

Perfetti, C. A., \& Liu, Y. (2005). Orthography to phonology and meaning: Comparisons across and within writing systems. Reading and Writing, 18, 193-210.

Perfetti, C. A., Liu, Y., Fiez, J., Nelson, J., Bolger, D. J., \& Tan, L. H. (2007). Reading in two writing systems: Accommodation and assimilation of the brain's reading network. Bilingualism: Language and Cognition, 10, 131-146. 
Perry, C., Ziegler, J. C., \& Zorzi, M. (2010). Beyond single syllables: Large-scale modeling of reading aloud with the Connectionist Dual Process (CDP++) model. Cognitive Psychology, 61, 106-151. doi: 10.1016/j.cogpsych.2010.04.001

Peyrin, C., Démonet, J. F., N'Guyen-Morel, M. A., Le Bas, J. F., \& Valdois, S. (2011). Superior parietal lobe dysfunction in a homogeneous group of dyslexic children with a visual attention span disorder. Brain and Language, 118, 128-138.

Peyrin, C., Lallier, M., Demonet, J. F., Pernet, C., Baciu, M., Le Bas, J. F., \& Valdois, S. (2012). Neural dissociation of phonological and visual attention span disorders in developmental dyslexia: fMRI evidence from two case reports. Brain and Language, 120, 381-394.

Peyrin, C., Lallier, T., \& Valdois, S. (2008). Visual attention span brain mechanisms in normal and dyslexic readers. In M. Baciu (Ed.), Neuropsychology and cognition of language: Behavioural, neuropsychological and neuroimaging studies of spoken and written language (pp. 22-43). Thiruvananthapuram: Research Signpost.

Poeppel, D. (2003). The analysis of speech in different temporal integration windows: Cerebral lateralization as "asymmetric sampling in time”. Speech Communication, 41, 245-255.

Protopapas, A. (2014). From temporal processing to developmental language disorders: Mind the gap. Philosophical Transactions of the Royal Society B, 369, 20130090.

Pugh, K. R., Mencl, W. E., Jenner, A. R., Katz, L., Frost, S. J., Lee, J. R., ...Shaywitz, B. A. (2000). Functional neuroimaging studies of reading and reading disability (developmental dyslexia). Mental Retardation and Developmental Disabilities Research Reviews, 6, 207-213.

Ramus, F. (2014). Neuroimaging sheds new light on the phonological deficit in dyslexia. Trends in Cognitive Sciences, 18, 274-275. doi: 10.1016/j.tics.2014.01.009

Ramus, F., Rosen, S., Dakin, S. C., Day, B. L., Castellote, J. M., White, S., \& Frith, U. (2003). Theories of developmental dyslexia: Insights from a multiple case study of dyslexic adults. Brain, 126, 841-865.

Ramus, F., \& Szenkovits, G. (2008). What phonological deficit? Quarterly Journal of Experimental Psychology, 61, 129-141. doi: 10.1080/17470210701508822

Rau, A. K., Moll, K., Moeller, K., Huber, S., Snowling, M. J., \& Landerl, K. (2016). Same same, but different: Word and sentence reading in German and English. Scientific Studies of Reading, 20, 203-219. doi:10.1080/10888438.2015.1136913

Rau, A. K., Moll, K., Snowling, M. J., \& Landerl, K. (2015). Effects of orthographic consistency on eye movement behavior: German and English children and adults process the same words differently. Journal of Experimental Child Psychology, 130, 92-105.

Reilhac, C., Peyrin, C., Démonet, J. F., \& Valdois, S. (2013). Role of the superior parietal lobules in letter-identity processing within strings: fMRI evidence from skilled and dyslexic readers. Neuropsychologia, 51, 601-612.

Rey, A., \& Schiller, N. O. (2005). Graphemic complexity and multiple print-to-sound associations in visual word recognition. Memory \& Cognition, 33, 76-85.

Richlan, F. (2014). Functional neuroanatomy of developmental dyslexia: The role of orthographic depth. Frontiers in Human Neuroscience, 8, 347. doi:10.3389/fnhum.2014.00347

Richlan, F., Kronbichler, M., \& Wimmer, H. (2009). Functional abnormalities in the dyslexic brain: A quantitative meta-analysis of neuroimaging studies. Human Brain Mapping, 30, 3299-3308.

Richlan, F., Kronbichler, M., \& Wimmer, H. (2011). Meta-analyzing brain dysfunctions in dyslexic children and adults. NeuroImage, $56,1735-1742$

Saiegh-Haddad, E., \& Geva, E. (2010). Acquiring reading in two languages: An introduction to the special issue. Reading and Writing, 23, 263-267.

Saksida, A., Iannuzzi, S., Bogliotti, C., Chaix, Y., Démonet, J. F., Bricout, L.,...George, F. (2016). Phonological skills, visual attention span, and visual stress in developmental dyslexia. Developmental Psychology, 52, 1503-1516.

Sandak, R., Mencl, W. E., Frost, S. J., \& Pugh, K. R. (2004). The neurobiological basis of skilled and impaired reading: Recent findings and new directions. Scientific Studies of Reading, 8, 273-292.

Schlaggar, B. L., \& McCandliss, B. D. (2007). Development of neural systems for reading. Annual Review of Neuroscience, 30, 475-503.

Schmalz, X., Marinus, E., Coltheart, M., \& Castles, A. (2015). Getting to the bottom of orthographic depth. Psychonomic Bulletin \& Review, 22, 1614-1629. doi:10.3758/s13423-015-0835-2

Schmalz, X., Robidoux, S., Castles, A., Coltheart, M., \& Marinus, E. (2017). German and English bodies: No evidence for crosslinguistic differences in preferred orthographic grain size. Collabra: Psychology, 3, 5.

Seymour, P. H., Aro, M., \& Erskine, J. M. (2003). Foundation literacy acquisition in European orthographies. British Journal of Psychology, 94, 143-174.

Share, D. L. (1999). Phonological recoding and orthographic learning: A direct test of the self-teaching hypothesis. Journal of Experimental Child Psychology, 72, 95-129.

Share, D. L. (2004). Orthographic learning at a glance: On the time course and developmental onset of self-teaching. Journal of Experimental Child Psychology, 87, 267-298.

Skottun, B. C., \& Skoyles, J. R. (2006). Attention, reading and dyslexia. Clinical and Experimental Optometry, 89, 241-245.

Snowling, M. J. (2000). Dyslexia (2nd ed.). Malden, MA: Blackwell.

Snowling, M. J. (2008). Specific disorders and broader phenotypes: The case of dyslexia. Quarterly Journal of Experimental Psychology, 61, $142-156$.

Steinbrink, C., Vogt, K., Kastrup, A., Müller, H. P., Juengling, F. D., Kassubek, J., \& Riecker, A. (2008). The contribution of white and gray matter differences to developmental dyslexia: Insights from DTI and VBM at 3.0 T. Neuropsychologia, 46, 3170-3178.

Taylor, J. S. H., Rastle, K., \& Davis, M. H. (2013). Can cognitive models explain brain activation during word and pseudoword reading? A meta-analysis of 36 neuroimaging studies. Psychological Bulletin, 139, 766-791. doi:10.1037/a0030266

Thiebaut de Schotten, M., Cohen, L., Amemiya, E., Braga, L. W., \& Dehaene, S. (2014). Learning to read improves the structure of the arcuate fasciculus. Cerebral Cortex, 24, 989-995. doi:10.1093/ cercor/bhs 383

Vaessen, A., Bertrand, D., Tóth, D., Csépe, V., Faísca, L., Reis, A., \& Blomert, L. (2010). Cognitive development of fluent word reading does not qualitatively differ between transparent and opaque orthographies. Journal of Educational Psychology, 102, 827-842. doi:10. 1037/a0019465

Valdois, S., Bosse, M.-L., Ans, B., Carbonnel, S., Zorman, M., David, D., \& Pellat, J. (2003). Phonological and visual processing deficits can dissociate in developmental dyslexia: Evidence from two case studies. Reading and Writing, 16, 541-572.

Valdois, S., Peyrin, C., Lassus-Sangosse, D., Lallier, M., Démonet, J. F., \& Kandel, S. (2014). Dyslexia in a French-Spanish bilingual girl: Behavioural and neural modulations following a visual attention span intervention. Cortex, 53, 120-145.

van Atteveldt, N., \& Ansari, D. (2014). How symbols transform brain function: A review in memory of Leo Blomert. Trends in Neuroscience and Education, 3, 44 49.

van der Mark, S., Klaver, P., Bucher, K., Maurer, U., Schulz, E., Brem, S., ...Brandeis, D. (2011). The left occipitotemporal system in reading: Disruption of focal fMRI connectivity to left inferior frontal and inferior parietal language areas in children with dyslexia. NeuroImage, 54, 2426-2436.

Vandermosten, M., Boets, B., Poelmans, H., Sunaert, S., Wouters, J., \& Ghesquière, P. (2012). A tractography study in dyslexia: Neuroanatomic correlates of orthographic, phonological and speech processing. Brain, 135, 935-948. 
Vigneau, M., Beaucousin, V., Herve, P. Y., Duffau, H., Crivello, F., Houde, O.,...Tzourio-Mazoyer, N. (2006). Meta-analyzing left hemisphere language areas: Phonology, semantics, and sentence processing. NeuroImage, 30, 1414-1432.

White, S., Milne, E., Rosen, S., Hansen, P., Swettenham, J., Frith, U., \& Ramus, F. (2006). The role of sensorimotor impairments in dyslexia: A multiple case study of dyslexic children. Developmental Science, 9, 237-255, disc. 265-269. doi:10.1111/j.1467-7687.2006.00483.x

Wolf, M., \& Bowers, P. G. (1999). The double-deficit hypothesis for the developmental dyslexias. Journal of Educational Psychology, 91, 415-438. doi:10.1037/0022-0663.91.3.415

Wydell, T. N., \& Butterworth, B. (1999). A case study of an EnglishJapanese bilingual with monolingual dyslexia. Cognition, 70, 273305 .

Yeatman, J. D., Rauschecker, A. M., \& Wandell, B. A. (2013). Anatomy of the visual word form area: Adjacent cortical circuits and longrange white matter connections. Brain and Language, 125, 146155.

Yeatman, J. D., Weiner, K. S., Pestilli, F., Rokem, A., Mezer, A., \& Wandell, B. A. (2014). The vertical occipital fasciculus: A century of controversy resolved by in vivo measurements. Proceedings of the National Academy of Sciences, 111, E5214-E5223.

Yoncheva, Y. N., Zevin, J. D., Maurer, U., \& McCandliss, B. D. (2010). Auditory selective attention to speech modulates activity in the visual word form area. Cerebral Cortex, 20, 622-632.

Ziegler, J. C., Bertrand, D., Tóth, D., Csépe, V., Reis, A., Faísca, L., Blomert, L. (2010). Orthographic depth and its impact on universal predictors of reading a cross-language investigation. Psychological Science, 21, 551-559.

Ziegler, J. C., \& Goswami, U. (2005). Reading acquisition, developmental dyslexia, and skilled reading across languages: A psycholinguistic grain size theory. Psychological Bulletin, 131, 3-29. doi:10. 1037/0033-2909.131.1.3

Ziegler, J. C., Perry, C., \& Zorzi, M. (2013). Modelling reading development through phonological decoding and self-teaching: Implications for dyslexia. Philosophical Transactions of the Royal Society B, 369, 20120397. doi:10.1098/rstb.2012.0397

Zoubrinetzky, R., Bielle, F., \& Valdois, S. (2014). New insights on developmental dyslexia subtypes: Heterogeneity of mixed reading profiles. PLoS ONE, 9, e99337. doi:10.1371/journal.pone.0099337 